\title{
The Babysitter: A Feminist Interpretation
}

\author{
LIU Ke-dong, LI Shuang-shuang \\ Harbin Institute of Technology, Harbin, China
}

\begin{abstract}
Sexual violence, a prevalent problem in the spousal relationship, is closely related to the issue of female consciousness. In The Babysitter, Coover (1989) tells of a teenage girl babysitting two kids and a baby and of two of her male peers and the children's father altogether exploring their obsession towards her and, moreover, traces the evaluation and devaluation of women to the presentation of TV exploring its influence on his heroines, namely Mrs. Tucker and the babysitter serving as victims of the patriarchal society. Through a close engagement with the sexual objectification theory, this paper analyzes in detail men's aggressive oppressions upon women as well as women's compromise and rebellion towards the sexual violence, and investigates that the awakening of female independent consciousness is a key factor in effectively helping women achieve the gender equality between sexes.
\end{abstract}

Keywords: Robert Coover, The Babysitter, objectification

\section{Introduction}

Robert Coover, a representative post-modern writer of "fabulation" and "metafiction" who harbors sincere fondness for weaving visual arts into his written works. When he was teaching at Brown University, Coover started doing experimental writing on electronic fiction, during which time The Babysitter (1989) emerges. The story is divided into 108 segments that are not arranged in chronological order. Generally, it is an account of events taking place in three separate places from 7:40 to 10:00 at night. With everything pointing to uncertainty or indeterminacy to the end of the story, "most of what happened before happens again with new variations" (Evenson, 2003, p. 92). The reader can be certain only that the babysitter arrives at the Tuckers' home, and that the Tuckers leave their home for a party, and Jack and Mark play pinball at a drugstore. The rest of the story amounts to an indefinite number of situations based on these givens. Generally speaking, the meta-fictional story tells of a teenaged girl babysitting two kids and a baby for a couple during one night, and of two of her male peers and the children's father exploring their delusional and realistic obsessions towards her.

Within the framework of feminism, which challenges the patriarchal society, struggling for recognition of the claims of women for legal, political, familial, etc. rights equal to those possessed by men, this paper explores the concern of American contemporary life including the lust both in the real and imagined events of the modern man, the self-image of women viewing themselves through the lens of external observers, and the sexual violence repressing the growth of female independent consciousness or the opposite.

LIU Ke-dong, Ph.D., professor of English, School of Foreign Languages, Harbin Institute of Technology. LI Shuang-shuang, master degree, School of Foreign Languages, Harbin Institute of Technology. 


\section{Mr. Tucker, Mark, and Jack: Objectifying Sex}

The concept of "sexual objectification” and, particularly, the objectification of women is an important idea in feminist theory derived from feminism. Sexual objectification is defined as:

The act of disregarding the personal and intellectual abilities and capabilities of a female, and reducing a woman's worth or role in society to that of an instrument for the sexual pleasure that she can produce in the mind of another. (Barry, 1994, p. 247)

In patriarchal societies men tend to treat women as their sexual objects, from whom they get pleasure. The male figures including Mr. Tucker, Jack, and Mark following this trend, exhibit their sexual desire towards the babysitter, and their infatuation objectifies the social evaluation of women.

Attention has been focused on the female body as a source of sexual attraction. Mr. Tucker indulges himself in the fantasy of the babysitter's bare body throughout the night. As soon as the babysitter shows up, Mr. Tucker constantly imagines about the babysitter's "soft wet breasts", "pale and ripply tummy", and "light brown public hair”, for he has happened to see her naked body in the tub before. On the drive to the party, Mr. Tucker's mind is partly on the girl who seems to be "arching her back, jutting her pert breasts, twitching her thighs" (Coover, 1989, p. 185). He recalls his long past, those days when he is young and energetic; most importantly, he is satisfied with his wife's fine body which now turns fatty and has to be tightened by girdles to keep it good-looking. Sitting along with his wife in the car, he could not stop thinking about the babysitter's "bare thighs, no girdles, nothing up there but a flimsy pair of panties and soft adolescent flesh” (Coover, 1989, p. 187).

The continuous imagining about female body can trigger men's libido and lead to their sexual advances. At the party, overdrunk, Mr. Tucker's mind wanders between his fantasy and the reality, constantly imagining the babysitter's naked body and their entanglements in the bathroom. He dreams that "she huddles in his arms like a child. Lovingly, paternally, knowledgeably, he wraps her nakedness" (Coover, 1989, p. 192), imagines that "he squeezes her close between his thighs, pulls her back toward him, one hand sliding down her tummy between her legs" (Coover, 1989, p. 196) and fantasizes that his innocent wife runs into his affair with the babysitter. Lost in his fantasy, Mr. Tucker could not help speaking out some filthy words in public. "I dream of Jeannie with the light brown public hair!” (Coover, 1989, p. 191). Mr. Tucker adores the body of the babysitter, which results in his secretly returning home and raping her.

Jack is the babysitter's boyfriend and longs for a more intimate relationship with her. Like Mr. Tucker, he adores the "soft" and "fragrant" body of the babysitter. Jack's attitude towards his girlfriend is a bit different from the others. Generally speaking, Jack shows respect for the babysitter and their relationship is relatively based on the unstable equilibrium. He has been to Tuckers' house while the babysitter is babysitting, but only "make[s] out a little" (Coover, 1989, p. 184). His stare implicates his sexual desire towards the babysitter but he consciously avoids going too far, for he would try his best to "care for her and would protect her, would shield her, if need be, with his own body” (Coover, 1989, p. 185). In spite of this, Jack agrees to rape his girlfriend along with his friend Mark after balancing his resistance and obedience to his sexual impulse. The dramatic transition is when Jack saves the babysitter from being raped by Mark and Mr. Tucker.

Mark is Jack's friend who is the one accompanying Jack in the drugstore during that night. He is the son of the party holder and a member of a middle-class family, obviously showing no interest in the party his father 
holds. Wondering what to do in his spare time, Mark proposes to rape the babysitter with Jack. Finally he manages to persuade Jack to carry out their evil plan.

All the male characters, Jack, Mark as well as Mr. Tucker even the little Jimmy who is the son of Mr. Tucker explore sexual advances towards the female body, which is meant to be the babysitter's. Their objectifying sex dehumanizes women and reflects the reality that women turn out to be considered as composites of attractive parts rather than complete, multi-dimensional people that can be appreciated intellectually.

\section{Mrs. Tucker: In Self-objectification}

Objectification theory posits that "women are typically acculturated to internalize an observer's perspective as a primary view of their physical selves” (Fredrickson \& Roberts, 1997, p. 173). The reason why women habitually monitor their bodies results from the fact that they are more identified and associated with their bodies and to a great extent they are valued for how they look. In order to win social acceptability, women are under constant pressure to correct their bodies and appearances, making them sensually pleasing to men regardless of those experimental consequences associated such as body shame, appearance anxiety, depression, disordered eating. Mrs. Tucker, namely Dolly, being female in a culture that pervasively objectifies the female body, serves as a victim of patriarchal society in objectifying herself.

Women who experience body dissatisfaction would try to alter the appearance of their bodies. Mrs. Tucker is a middle-aged housewife, the selfless mother of three children and meanwhile the sacred slaver of her husband. Influenced by her husband's preference of female body image, Mrs. Tucker is consistently checking or rearranging her appearance to ensure that they are presentable. In order to comply with her husband's sexual expectations, Mrs. Tucker engages in actions which intends to change the appearance of her body by using the garters to shape it. On the drive to the party, Mrs. Tucker seems to "adjust a garter", "readjust a garter" and "pull a stocking tight, biting deeper with the garters" while her husband "stumbles" to answer the question she proposes: "What do you think of our babysitter?" (Coover, 1989, p. 186). Obviously, she cares about what she looks like in her husband's eyes, which accounts for her covering out-shaped body regardless of the pain from wearing the girdle and its detrimental outcome to her physical health. "And fat. Not just tight, her girdle actually hurts. Somewhere recently she's read about women getting heart attacks or cancer or something from too-tight girdles" (Coover, 1989, p. 186).

Apart from physical pain, women experience mental depression as well, feeling ashamed of their unsatisfying bodies. Body shame is "a byproduct of the concept of an idealized body type adopted by most Western cultures that depicts a thin, model-type figure” (Fredrickson \& Roberts, 1997, p. 174). During the break at the party, Dolly takes advantage of the retreat to ease her girdle down a while and gets her a few good deep breaths. Unfortunately, she fails to get herself back into the girdle. Therefore, there is a game about "Get Dolly Tucker Back in Her Girdle Again”. Humiliated by exposing part of her body in public and acting like a clown playing at the show, Mrs. Tucker develops a sense of body shame and anxiety from which a feeling of helplessness is created in relation to correcting her physical appearance and helplessness in being able to control the way in which others perceive their appearance. Hearing about other guests' salting away their mothers in the rest room, Mrs. Tucker develops a picture of her being carted off to a rest home in a wheelbarrow and wonders if her husband would actually do that to her. "Harry, you won't let them take me to a rest home, will you, 
Harry?”(Coover, 1989, p. 205). It can be seen from here that Mrs. Tucker emotionally depends on her husband and begs for his staying with her.

Mrs. Tucker, being female in a culture in which man has been accustomed to repressing women, making them ashamed and leading them to "be their own enemies, to mobilize their immense strength against themselves, to be the executants of their virile needs" (Cixous, 1976, p. 878), tends to compromise with the oppressive ideology in valuing herself in accordance with the evaluation of her husband, Mr. Tucker. In the quest to achieve idealized beauty, Mrs. Tucker shapes her fatty body with girdles to please her husband regardless of physical and mental health risks. The subservience to her husband is attributed to her failure to achieve independence in personality.

\section{The Babysitter: Against Sexual Victimization}

More direct consequences of objectification to women are related to sexual victimization or violence. Rape is regarded as one of those traumatic experiences. Brownmiller (1975) argues in his book Against Our Will that rape is nothing more or less than "a conscious process of intimidation by which all men keep all women in a state of fear” (p. 15). The babysitter, a financially self-reliant and mentally open-minded teenage girl, is another female character in the short story victimized more or less by the sexual violence of male characters, including her boyfriend Jack, Jack's friend Mark and Mr. Tucker, in the process of being raped. Serving as a traditional concept of renegade, the babysitter strives for the recognition of women's basic rights in struggling against those corporal oppressions.

Economic independence helps develope female independent consciousness. The babysitter plays an active role in her relationship with her boyfriend Jack. Thanks to the job of babysitting, she does not have to live on Jack, which earns her the equality in their relationship. The couple tends to negotiate with each other in terms of their different opinions on one single issue. When Jack plans to see her in Tucker's house, he calls her on the phone to ask for permission. The babysitter refuses to let Jack and Mark come over after telling them they can.

In her sexual relationship with Jack and Mark, the babysitter never submits to their sexual satisfaction. There exists the possibility that Jack and Mark intend to rape the babysitter together. It proves that she tries her best to fight against them rather than being compliant to their sexual desire. “'Stop it!' she screams. 'Please, stop!' She’s on her hands and knees, trying to get up, but they're too strong for her” (Coover, 1989, p. 196). The babysitter rejects them by crying out and fighting back which shows her struggle against sexual abuse in the male-dominated society.

When it comes to her relationship with Mr. Tucker, there exist two contradictory endings of his rape of the babysitter given by Robert Coover: either the death of the babysitter or the obfuscation of Mr. Tucker, both of which exhibit the babysitter's rebellious attitude towards the sexual assault. The babysitter is bathing in the tub when Mr. Tucker faithfully breaks into the bathroom. Shocked, the girl grabs for a towel to cover her naked body out of self-protection. Having imagined his sexual advance with the babysitter to be pleasing, Mr. Tucker realizes that "that's not how it’s supposed to happen" (Coover, 1989, p. 203). As a result, he yanks away the towel and tries to command the girl: "Lift your legs up, honey. Put them around my back” (Coover, 1989, p. 201). Instead, the babysitter screams, trying to get rid of him. Regardless of the struggle of the babysitter, Mr. Tucker persists to rape the poor girl by "embracing her savagely”, "clutching roughly at her backside”; and "pushing something 
between her legs, hurting her" (Coover,1989, p. 203). The babysitter is slammed by "something cold and hard in the back" (Coover, 1989, p. 203) cracking her skull, and in consequence she seems to be sinking into the tub filled with water. Another scene juxtaposed simultaneously is that Mr. Tucker happens to "slip on the bathroom tiles, and crash to his ass, whacking his head on the way down” (Coover, 1989, p. 203), which lead to his passing out.

In the historical view,

The roles and privileges accorded to women are inferior to those assigned to men, and as much, sexism plays a central role in the continuing oppression of women, reducing women to being nothing more than objects to be won, prizes to be shown off, and playthings to be abused. (Swami et al., 2010, p. 366)

The babysitter plays a prominent role in consciously controlling her sexuality and subverting femininity which is socially constructed and internalized as gentleness, tolerance, compassion and deference, endeavoring to fight against sexual victimization oppressed by patriarchal males. She represents one of those who have developed female independent consciousness and endeavored to escape from the internalized role of women formed by historical circumstances, aspiring to full membership in the human space.

\section{Conclusion}

Objectification theory provides an important framework for understanding women's living conditions in a sociocultural context that sexually objectifies the female body and equates a woman's value with her body's appearance. The American culture is one that is measured on a patriarchal scale where the exploitative and oppressive relationship between sexes prevails, in which women are required to act out their sex roles in the repressive relations of subordination.

In juxtaposing fragments of Jack’s saving the babysitter from being raped by Mark; Jack and Mark’s raping the babysitter; Mr. Tucker's imagining himself seducing and making love with the babysitter; his catching Jack making love to the babysitter then raping her himself; catching the boys raping the babysitter and sending Jack home without clothing to the reader, Coover manages to articulate the subjection of women in the patriarchal society, either shaping themselves for the sake of others or being offended by men. In The Babysitter, on the one hand, women's role of subordination can be seen from the flat character Mrs. Tucker, a middle-class housewife whose existence is out of practicality. The unequal division of labor by the mainstream culture leaves her into the role of "the babysitter" and housekeeper bothered by daily trivial stuffs. She feels ashamed of her body's appearance based on her husband's evaluation of beauty, thus trying to shape it regardless of the physical pain. On the other hand, women's role of resistance can be seen from the babysitter. Faced with the sexual violence from Jack, Mark or Mr. Tucker, the babysitter strives to struggle against the force of the patriarchal society. Their difference lies on the fact that Mrs. Tucker yields to the prejudiced devaluation while the babysitter defends herself from the sexual victimization. Women have to develop the independent consciousness to construct a unique female discourse and culture. 


\section{References}

Barry, K. (1994). Female sexual slavery. New York: NYU Press.

Brownmiller, S. (1975). Against our will: Men, women, and rape. New York: Ballantine Books.

Cixous, H., Cohen, K., \& Cohen, P. ( 1976). The laugh of the Medusa. Signs, 1(4), 875-893.

Coover, R. (1989). The babysitter. New York: Oxford University Press.

Evenson, B. (2003). Understanding Robert Coover. Columbia, South Carolina: University of South Carolina Press.

Fredrickson, B. L., \& Roberts, T. A. (1997). Objectification theory: Toward understanding women's lived experiences and mental health risks. Psychology of Women Quarterly, 21(2), 173-206.

Kavka, M. (2001). Introduction. In E. Bronfen, \& M. Kavka (Eds.), Feminist consequences: Theory for the new century (pp. ix-xxvi). New York: Columbia University Press.

Mary, V. B. (1982). “Femininity,” “Masculinity,” and “Androgyny”: A modern philosophical discussion. Washington: Rowman and Littlefield.

Smolak, L. (1996). National eating disorders association/next door neighbors puppet guide book. International Journal of Eating Disorders, 18(3), 209-219.

Swami, V., Coles, R., Wilson, E., Salem, N., Wyrozumska, K., and Furnham, A. (2010). Oppressive beliefs at play: Associations among beauty ideals and practices and individual differences in sexism, objectification of others, and media exposure. Psychology of Women Quarterly, 34(3), 365-379. 